\title{
Pre-autoimmune thyroid abnormalities in the biobreeding diabetes-prone (BB-DP) rat: a possible relation with the intrathyroid accumulation of dendritic cells and the initiation of the thyroid autoimmune response
}

\author{
P J Simons, F G A Delemarre, P H M Jeucken and H A Drexhage \\ Department of Immunology, Erasmus University, Rotterdam, The Netherlands \\ (Requests for offprints should be addressed to P J Simons, Lab. Ee 838, Department of Immunology, Faculty of Medicine, Erasmus University Rotterdam, \\ P O Box 1738, 3000 DR Rotterdam, The Netherlands)
}

\begin{abstract}
Thyroid autoimmune reactions start with an accumulation of mainly dendritic cells in the thyroid. There is increasing evidence that, apart from being antigen-presenting cells, they are also able to control the growth and hormone synthesis of neighbouring endocrine cells. The questions thus arise: are dendritic cells accumulating in the pre-autoimmune thyroid in response to an altered proliferative or metabolic activity of thyrocytes, and do cytokines, monocyte chemoattractants, or both, have a role in their accumulation? We have investigated these questions in thyrocytes of the biobreeding diabetes-prone (BB-DP) rat in relation to the start of the intrathyroid accumulation of dendritic cells - that is, at about 9 weeks of age.

BB-DP rats and Wistar rats (controls) were studied from 3 to 20 weeks of age. Hyperplastic goitre development was studied by assessing the thyroid weight and by measuring the number of thyrocyte nuclei per $0.01 \mathrm{~mm}^{2}$ thyroid section. In addition, the in situ expression of interleukin-6 (IL-6), tumour necrosis factor- $\alpha$ (TNF- $\alpha$ ), monocyte-chemotactic protein-1 (MCP-1), and intercellular adhesion molecule-1 (ICAM-1) were studied by immunohistochemistry. The in vitro proliferative capacity of BB-DP and Wistar thyrocytes was measured by tritiated-thymidine $\left(\left[{ }^{3} \mathrm{H}\right] \mathrm{TdR}\right)$ and bromodeoxyuridine (BrdU) incorporation into reconstituted, TSHand non-TSH-stimulated, cultured thyroid follicles. Further in vitro studies consisted of measurement of the production of thyroxine $\left(\mathrm{T}_{4}\right)$, triiodothyronine $\left(\mathrm{T}_{3}\right)$, thyroglobulin, IL-6, TNF- $\alpha$ and MCP-1 by the thyroid follicles.

BB-DP rats developed a small hyperplastic goitre between the ages of 9 and 12 weeks. The in vitro proliferative rate of thyrocytes isolated from hyperplastic BB-DP thyroids was significantly lower than that of Wistar thyrocytes. This phenomenon also occurred in
\end{abstract}

follicles isolated from BB-DP rats before hyperplastic goitre development, which produced significantly less $\mathrm{T}_{4}$, but more $\mathrm{T}_{3}$, than did Wistar follicles of the same age. At the time of and after hyperplastic goitre development, BB-DP follicles exhibited altered metabolic behaviour and produced significantly more $T_{4}$, but equal amounts of $\mathrm{T}_{3}$ compared with both Wistar follicles of the same age and follicles of younger BB-DP rats (both under basal conditions and TSH-stimulated). In vitro IL-6 production by these BB-DP thyroid follicles was also increased. There was no noteworthy difference in production of thyroglobulin and MCP-1 between BB-DP and Wistar follicles at any age. TNF- $\alpha$ was not produced by BB-DP or Wistar thyroid follicles.

Immunohistochemistry revealed the expression of IL-6 by both BB-DP and Wistar thyroid follicle cells at all times of sampling. MCP-1 and TNF- $\alpha$ were expressed only when infiltrates were present in BB-DP thyroids (restricted to leucocytes, ages $>18$ weeks). Modest ICAM-1 expression was restricted to large blood vessels in both BB-DP and Wistar thyroids; in the case of infiltrates (BB-DP rat) alone, high ICAM-1 expression was found on blood vessels and leucocytes in these infiltrations.

At the time of intrathyroidal dendritic cells accumulation, BB-DP rats develop a small hyperplastic goitre. At that time there is also in vitro evidence for a shift to a higher production of thyroxine and IL-6 from thyrocyte follicles. The in vitro proliferation rate of BB-DP thyrocytes is, however, abnormally low (both in the pre- and hyperplastic period). Similar pre-autoimmune thyroid growth abnormalities have been described in another animal model of thyroid autoimmune disease, the obese strain chicken.

Journal of Endocrinology (1998) 157, 43-51 


\section{Introduction}

The animal models of spontaneously developing autoimmune thyroid disease (AITD) are the biobreeding diabetes-prone (BB-DP) rat, the non-obese diabetic (NOD) mouse and the obese strain (OS) chicken. The first immunological sign of AITD in these three animal models is an accumulation of antigen-presenting cells (APCs), mainly dendritic cells, in the thyroid (Voorbij et al. 1990, Many et al. 1995, Hala et al. 1996). This accumulation of APCs precedes the triggering of autoreactive $\mathrm{T}$ and $\mathrm{B}$ lymphocytes in the thyroid-draining lymph nodes and the subsequent influx of $\mathrm{T}$ and $\mathrm{B}$ lymphocytes into the thyroid (focal thyroiditis; Voorbij et al. 1990, Many et al. 1995). High numbers of APCs can also be detected in human forms of AITD, Hashimoto's and Graves' goitres (Kabel et al. 1988). In Graves' goitres, dendritic cells often accumulate in the absence of a noteworthy lymphocytic infiltration (Kabel et al. 1988). The question thus arises: "Why do dendritic cells start to accumulate in thyroid glands that later become the target of an autoimmune attack?'

For a further exploration of this question it is important to note that endocrine tissues normally contain dendritic cells and macrophages. Although dendritic cells are present in low numbers in the normal thyroid (Kabel et al. 1988, Mooij et al. 1993a), networks of relatively large numbers can be found in the anterior pituitary (Allaerts et al. 1996, 1997) and in the gonads (Brännström \& Norman 1993, Hoek et al. 1996). In the anterior pituitary, dendritic cells form a subgroup of the network of folliculo-stellate cells (Allaerts et al. 1996). Apart from being excellent accessory cells in $\mathrm{T}$ cell stimulation, these dendritic cells are also capable of regulating the hormonal responses of neighbouring endocrine cells (Allaerts et al. 1994, 1996, 1997). The cytokine, interleukin-6 (IL-6), is believed to have an important role in this regulation (Allaerts et al. 1994, 1997). With regard to the presence of dendritic cells and macrophages in the ovary and testis, these classical APCs have a role not only in the regulation of ovulation (Brännström \& Norman 1993), but also in the growth and steroid production of granulosa, theca, luteal and Leydig cells (Gaytan et al. 1995, Hoek et al. 1996, Katabuchi et al. 1996). Recently, we have obtained preliminary evidence that dendritic cells are also involved in the regulation of the growth of thyrocytes: Wistar rat splenic dendritic cells - which are excellent APCs - were capable of downregulating the uptake of tritiated thymidine $\left(\left[{ }^{3} \mathrm{H}\right] \mathrm{TdR}\right)$ and bromodeoxyuridine (BrdU) of Wistar rat thyrocytes kept in follicle culture (manuscript in preparation). Interestingly, dendritic cells accumulate in the thyroid during goitrous conditions, for example in simple human goitres (Kabel et al. 1988) and in iodine-deficient goitres both in humans (Wilders-Truschnig et al. 1989) and in the Wistar rat (Mooij et al. 1993a).
This accumulating evidence that dendritic cells have a role in the regulation of growth and hormone production of endocrine cells (Brännström \& Norman 1993, Allaerts et al. 1994, 1996, 1997, Gaytan et al. 1995, Hoek et al. 1996, Katabuchi et al. 1996), is highly suggestive that the accumulation of dendritic cells in thyroid glands, which later become the targets of an autoimmune reaction, may be a consequence of an abnormal proliferative rate or metabolic activity of pre-autoimmune thyrocytes. Interestingly, many papers have, indeed, reported preautoimmune abnormalities in the growth and function of thyrocytes of the OS chicken (reviewed by Sundick 1989).

In this study, we have investigated whether there are pre-autoimmune abnormalities in the proliferative rate and in the metabolic activity of BB-DP thyrocytes compared with Wistar thyrocytes. We studied hyperplastic goitre development (thyroid weight increase and the number of thyrocyte nuclei per area of histological thyroid section), uptake of $\left.{ }^{3} \mathrm{H}\right] \mathrm{TdR}$ in isolated and in vitro reconstituted thyroid follicles (verified by BrdU labelling), and the production of thyroxine $\left(\mathrm{T}_{4}\right)$, tri-iodothyronine $\left(\mathrm{T}_{3}\right)$, and thyroglobulin by isolated and in vitro reconstituted thyroid follicles.

Adhesion molecules on thyroid endothelial cells and locally produced cytokines/monocyte-chemokines in pre-autoimmune stages are probably instrumental in the enhanced attraction of dendritic cells (for which monocytes are among the important precursors, Mooij et al. 1994, Peters et al. 1996) into the BB-DP thyroid. Because of limited availability of antibodies, from all the various cytokines and growth factors involved in monocyte extravasation and the transition of monocytes to dendritic cells, we were able to study only intercellular adhesion molecule-1 (ICAM-1), monocyte chemotactic protein-1 (MCP-1), IL-6 and tumour necrosis factor- $\alpha$ (TNF- $\alpha$ ). ICAM-1 is one of the important endothelial adhesion molecules, MCP-1 is an important monocyte chemoattractant, and IL- 6 and TNF- $\alpha$ are, alongside granulocyte monocyte colony stimulating factor (GM-CSF) and IL-4, important cytokines for monocyte to dendritic cell transition (Peters et al. 1996). The IL-6, TNF- $\alpha$ and MCP-1 production by BB-DP thyrocytes, and the ICAM-1 expression in the BB-DP thyroid were studied in situ (immunohistochemistry) as well as in vitro (thyroid follicle cultures).

Data were analysed taking into account the time at which intrathyroid accumulation of dendritic cells begins in the BB-DP rat, which is at about 9 weeks of age (Voorbij et al. 1990, Mooij et al. 1993b).

\section{Materials and Methods}

\section{Animals}

BB-DP rats were bred for more than 20 generations in the Experimental Animal Centre of the Erasmus University 
Rotterdam, The Netherlands. The strain originates from the $\mathrm{BB} / \mathrm{WOR}$ strain via the $\mathrm{BB} /$ Organon strain. All rats were kept under controlled conditions of light (12 h light : $12 \mathrm{~h}$ darkness cycle) during the experiments. Between 12 and 20 weeks of age, $90 \%$ of our BB-DP rats develop $\alpha$-colloid antibodies detectable in serum, and during the same period $70-80 \%$ of our rats become diabetic (glucosuria). Normal pellets (Am-II, Hope Farms BV, Woerden, The Netherlands; $0.35 \mathrm{mg}$ iodine $/ \mathrm{kg}$ ) and tap water were available to all rats ad libitum. Control Wistar rats were purchased from Harlan, Zeist, The Netherlands.

Histology of the thyroid, quantification of histomorphological thyroid parameters and detection of cytokines in situ

BB-DP and Wistar rats were asphyxiated with carbon dioxide. Thyroid glands were excised, weighed and thereafter either immediately fixed overnight in a $10 \%(\mathrm{v} / \mathrm{v})$ formalin solution (for haematoxylin-eosin staining) or embedded in OCT (Tissue-Tek, Miles, Elkhart, IN, USA), snap-frozen in liquid nitrogen and stored at $-70{ }^{\circ} \mathrm{C}$ until required for immunohistochemistry.

The formalin-fixed tissues were processed routinely and embedded in paraffin. Serial sections $(6 \mu \mathrm{m})$ of blocks containing six separate thyroids were cut and routinely stained with haematoxylin-eosin. These sections were used to measure the thyrocyte nuclear areas and the number of thyrocyte nuclei per unit surface section area. For this purpose, a microscope (Axioscope, Zeiss, Weesp, The Netherlands) connected to a VIDAS-RT imageanalysis system (Kontron Elektronik $\mathrm{GmbH} /$ Zeiss) was used; magnifications were $\times 400$ and $\times 200$ respectively.

Immunostaining for cytokines was performed as described earlier (Eertwegh van den et al. 1991) with minor modifications. In short, cryostat sections $(8 \mu \mathrm{m})$ were cut, mounted on glass slides and kept overnight under high humidity at room temperature. Tissue sections were fixed for $10 \mathrm{~min}$ in acetone containing $0.02 \%(\mathrm{v} / \mathrm{v})$ $\mathrm{H}_{2} \mathrm{O}_{2}$ (Merck, Munich, Germany) to block endogenous peroxidase activity. Slides were dried and incubated with the primary antibody diluted in PBS (Merck) containing $0 \cdot 2 \%(\mathrm{v} / \mathrm{v})$ BSA (Organon Technika, Eppelheim, Germany) for $1 \mathrm{~h}$ at room temperature. The following polyclonal rabbit antibodies were used: anti-human IL-6 (1 : 10; Genzyme, Diagnostics, Cambridge, UK), antimouse TNF- $\alpha$ (1: 10; Genzyme) and anti-mouse MCP-1 (1:50; a kind gift from Dr R M Strieter; Paine et al. 1993). These antibodies crossreact with rat cytokines (Diamond \& Pesek 1991, Paine et al. 1993). For the detection of MCP-1, mouse anti-rat MCP-1 was also used (undiluted culture supernatant; a kind gift from Dr K Takahashi; Sakanashi et al. 1994). Immunostaining with anti-rat ICAM-1 (1:10; Cedarlane, Hornby, Ontario, Canada) was performed omitting the overnight step under high humidity. After incubation, slides were rinsed three times with $\mathrm{PBS}-0 \cdot 2 \% \mathrm{BSA}$ and subsequently further incubated with peroxidase-conjugated secondary antibodies (in PBS containing 1\% normal rat serum) and developed as described by Eertwegh van den et al. (1991).

\section{Isolation and in vitro culture of thyroid follicles}

Thyroid follicles were isolated according to slightly modified methods described in detail elsewhere (Denef et al. 1980, Spinel-Comez et al. 1990). The isolated follicles were resuspended under adherent conditions and cultured in 5-10 ml Ham's F12 medium (Gibco, BRL-Life Technologies, Breda, The Netherlands), supplemented with a five-hormone mixture (Ambesi-Impiombato et al. 1980) and $1 \%$ fetal calf serum (FCS). The viability of the isolated follicles was routinely assessed by the trypan blue exclusion test.

After reconstitution for $24 \mathrm{~h}$, the follicles were further cultured $\left(37^{\circ} \mathrm{C}, 5 \% \mathrm{CO}_{2}\right.$, water-saturated atmosphere) in 24-well plates (Costar Europe Ltd, Badhoevedorp, The Netherlands) in the presence of $0 \cdot 1 \mu \mathrm{M}$ KI (Merck) with or without various concentrations of bovine (b) thyroidstimulating hormone (TSH; Sigma Chemical Co., Axel, The Netherlands) or recombinant human (rh) TSH (Sigma; see Results). After $24 \mathrm{~h}$ the culture supernatants were aspirated, centrifuged at $500 \mathrm{~g}$ for $5 \mathrm{~min}$ and stored at $-20{ }^{\circ} \mathrm{C}$ until required for thyroid hormone, thyroglobulin or cytokine determinations.

The measurement of in vitro thyroid hormone, thyroglobulin and cytokine production

The $\mathrm{T}_{4}$ and $\mathrm{T}_{3}$ contents of the supernatants were measured by conventional radioimmunoassays (Dr T J Visser, Dr R Docter, Mr H van Toor, Department of Internal Medicine, University Hospital Dijkzigt, Rotterdam, The Netherlands). $\mathrm{T}_{3}$ and $\mathrm{T}_{4}$ standards were diluted in Ham's F12 culture fluid plus supplements. Each individual supernatant sample was assayed in duplicate.

Determination of the thyroglobulin concentrations in the follicle supernatants was performed using a newly developed sandwich ELISA. Microtitre plates (Falcon, Becton Dickinson Labware, New Jersey, USA) were coated overnight at $4{ }^{\circ} \mathrm{C}$ with a specific polyclonal antiserum against rat thyroglobulin in PBS $(4 \cdot 0 \mu \mathrm{g}$ protein A purified immunoglobulins per well). Non-specific binding was prevented by preincubating the plates with PBS $-0.5 \%$ BSA-0.05\% (v/v) Tween 20 (Merck) for $1 \mathrm{~h}$. Rat thyroglobulin $(31-2000 \mathrm{ng} / \mathrm{ml})$, which was used as a standard, and the culture supernatants were then diluted in Ham's F12 medium (plus supplements) and incubated for $1.5 \mathrm{~h}$. Finally, the plates were incubated during $1.5 \mathrm{~h}$ with a mixture of two monoclonal (mouse) antibodies against rat thyroglobulin $(1: 2000$ in PBS; clones $2 \mathrm{~F} 2$ and 2H11), followed by incubation for $1 \mathrm{~h}$ with a polyclonal anti-mouse serum conjugated with peroxidase $(1: 1000$ 
in PBS; DAKO, Glostrup, Denmark). Bound enzyme activity was measured with $0.05 \mathrm{M} \mathrm{KNaPO}_{4}$ (Merck) buffer ( $\mathrm{pH} 5 \cdot 6$ ) containing $6 \mathrm{mg} / \mathrm{ml}$ ortho-phenyldiamine dihydrochloride (Sigma) and $0.015 \% \mathrm{H}_{2} \mathrm{O}_{2}$ (Merck) as substrate. This reaction was stopped with $2 \mathrm{M} \mathrm{HCl}$ (Merck) and the optical density was read at $492 \mathrm{~nm}$. All incubation steps were performed at room temperature and between these steps the wells were washed at least three times with $0 \cdot 9 \%(\mathrm{w} / \mathrm{v}) \mathrm{NaCl}$ (Merck) $-0 \cdot 1 \%$ Tween 20 in aqua dest. Rat thyroglobulin and antibodies against this thyroglobulin were developed and kindly provided by $\mathrm{Dr}$ J J M de Vijlder, Academic Medical Centre, Department of Pediatrics, Amsterdam, The Netherlands.

IL-6 was detected in the B9 bioassay developed by Aarden et al. (1987). The murine fibroblast cell line, WEHI $164 \cdot 13$, was used to assay TNF bioactivity according to Espevik \& Nissen-Meyer (1986). Both techniques have been described in detail before. Thyroid follicle culture supernatants were serially diluted and assayed in triplicate.

Rat MCP-1 in the culture supernatants of the follicles was determined with a commercial available ELISA kit (Immunosource, Zoersal-Halle, Belgium) according to techniques advised by the manufacturer.

\section{The measurement of in vitro thyrocyte proliferation}

Thyroid follicles were labelled with $\left[{ }^{3} \mathrm{H}\right] \mathrm{TdR}$ during the last $5 \mathrm{~h}$ of culture. In brief, the follicles were washed and put on fresh Ham's F12 medium (plus supplements and different concentrations of bTSH) in 96-well plates (Costar). Subsequently, $1 \mu \mathrm{Ci} /$ well methyl- $\left[{ }^{3} \mathrm{H}\right] \mathrm{TdR}$ (Amersham International, Amersham, England) was added. After the period of labelling at $37^{\circ} \mathrm{C}$ in a $5 \% \mathrm{CO}_{2}$ water-saturated incubator, the follicles were harvested on filter paper and radioactivity was counted in a liquid scintillation analyser (LKB Betaplate; Wallac, Turku, Finland). In some experiments, follicles (obtained from both rat strains) were co-cultured with $5 \mu \mathrm{g} / \mathrm{ml}$ aphidicolin (an inhibitor of DNA polymerase; Sigma; Okugawa et al. 1995) or exposed to $2000 \mathrm{rad}$ Xirradiation. These treatments were applied to prevent replication of DNA, and thus to ensure that radioactivity measured in the samples that did not undergo these treatments reflected the S-phase of the cell cycle (Maurer 1981). Each individual experiment was performed in duplicate.

To validate further the $\left[{ }^{3} \mathrm{H}\right] \mathrm{TdR}$ incorporation assay, data were also confirmed with $\mathrm{BrdU}$ labelling. For that purpose, the follicles were incubated at $37^{\circ} \mathrm{C}$ in a $5 \% \mathrm{CO}_{2}$ water-saturated incubator in the presence of $10 \mu \mathrm{M}$ BrdU (BrdU-kit I; Boehringer) during the last $5 \mathrm{~h}$ of culture. Thereafter, the samples were thoroughly washed in PBS, cytocentrifuged onto glass slides, air-dried and fixed in pre-cooled 70\% (v/v) ethanol (Merck) for $30 \mathrm{~min}$ at $-20^{\circ} \mathrm{C}$. The $\mathrm{BrdU}$ incorporation was visualized immunocytochemically according to the instructions of the manufacturer. The percentage of BrdU-positive $\left(\mathrm{BrdU}^{+}\right)$follicles was evaluated by counting at least 500 follicles per sample. For negative controls, the primary incubation step was buffer solution without anti-BrdU antibody.

\section{Statistical analysis}

The results are presented as means \pm S.D. or S.E.M. (see Figures). Statistical analyses of the quantitative histomorphological measurements were performed using the Student's t-test (unpaired, two-tailed, InStat computer program). Statistical analyses of the production of hormones, thyroglobulin and cytokines and the proliferative rate of the in vitro cultured thyroid follicles were performed using Wilcoxon's rank sum test (two-tailed, InStat computer program).

\section{Results}

Thyroid weight and number of thyrocyte nuclei per surface area of a thyroid section

Figure 1a shows that, between the ages of 9-12 weeks, the thyroid weight of BB-DP rats became statistically greater than that of Wistar rats, and that the BB-DP rat thyroid continued to grow during our experimental period of 20 weeks, whereas the Wistar thyroid weight had reached a plateau from 9 weeks of age. From the age of 10 weeks onwards, morphological signs of thyroid hyperplasia in the BB-DP rat thyroid were evident: the number of thyrocyte nuclei per $0.01 \mathrm{~mm}^{2}$ thyroid section surface area was significantly greater in BB-DP rats than in Wistar rats (Fig. 1b). Lymphocytic infiltrations were observed in our BB-DP colony only from the age of 18 weeks, therefore lymphocytic accumulation did not contribute to goitre formation in this pre-autoimmune phase.

\section{In vitro thyrocyte proliferation}

During the $24 \mathrm{~h}$ of culture after the isolation procedure, fragmented follicles of both BB-DP and Wistar rats became sphere-like structures again, and contained 30-50 thyrocytes per follicle (judged by inverted microscopy and haematoxylin-eosin staining). There was no difference in the morphology between $\mathrm{BB}$ and Wistar follicles. Because our culture conditions were low in FCS, the basal-apical polarity was normal. The reconstituted follicles were washed and seeded in 24-well plates at a density of 1000 follicles/well. At this stage, $0 \cdot 1 \mu \mathrm{M} \mathrm{KI}$ and $\mathrm{bTSH}$ in concentrations ranging from $1 \times 10^{-5}$ to $5 \times 10^{2} \mathrm{mU} / \mathrm{ml}$ were added to the follicles. Cultures were also performed in the absence of bTSH. 

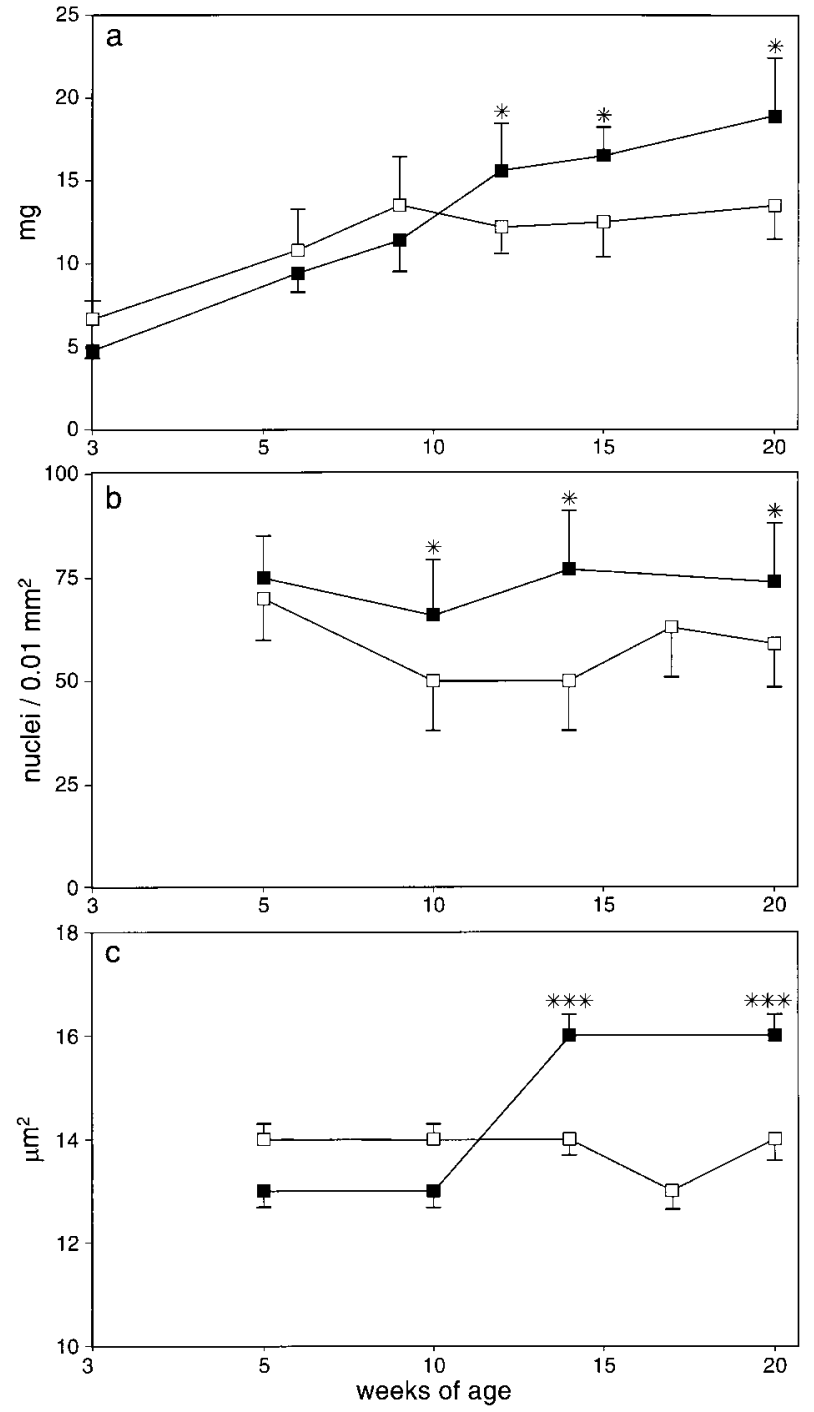

Figure 1 Thyroid weight (a), number of nuclei per section area (b, hyperplasia) and the nuclear areas (c, 'hypermetabolism') of BB-DP rats $(\square)$ and Wistar rats $(\square)$ at various ages. Means $(n \geq 30) \pm$ S.D. are shown. ${ }^{*} P<0 \cdot 05,{ }^{*} * * P<0 \cdot 001$ compared with age-matched Wistar rats (Student's $t$-test).

During the period of follicle reconstitution, there was scarcely any spontaneous and inducible uptake of $\left[{ }^{3} \mathrm{H}\right] \mathrm{TdR}$ (<100 c.p.m.). Preliminary experiments established a time-dependent effect of the bTSH-induced $\left[{ }^{3} \mathrm{H}\right] \mathrm{TdR}$ uptake in thyroid follicles from BB-DP and Wistar rats after reconstitution time. Maximum bTSHinduced $\left[{ }^{3} \mathrm{H}\right] \mathrm{TdR}$ uptake was obtained in cultures of $24 \mathrm{~h}$ duration. Exposure to bTSH increased the $\left[{ }^{3} \mathrm{H}\right] \mathrm{TdR}$ uptake in a dose-dependent manner in thyroid follicles from both strains, although optimal concentrations differed between the two strains (Fig. 2). Figure 2 also shows that the in vitro proliferative responses of BB-DP and Wistar follicles differed: BB-DP rat follicles showed a clearly lower $\left[^{3} \mathrm{H}\right] \mathrm{TdR}$ uptake than that in Wistar rat follicles. This lower uptake was found regardless of the times of sampling: BB-DP thyroid follicles isolated before or during hyperplastic goitre development both showed a decreased uptake. In view of the discrepancy between our in vivo and in vitro data, the specificity of the $\left[{ }^{3} \mathrm{H}\right] \mathrm{TdR}$ uptake with regard to DNA replication was demonstrated with aphidicolin and $\mathrm{X}$-irradiation treatment. Both antiproliferative treatments reduced $>80 \%$ (five separate experiments) of the total $\left[{ }^{3} \mathrm{H}\right]$-radioactivity in Wistar and BB-DP follicles when added to the cultures. This reduction could not be ascribed to cytotoxity of aphidicolin or X-irradiation: none of the follicles showed an increased trypan blue uptake or altered morphology, and furthermore, production of $\mathrm{T}_{3}$ remained unchanged (data not shown).

The data from BrdU labelling were compatible with those from $\left[{ }^{3} \mathrm{H}\right] \mathrm{TdR}$ uptake. The percentages of $\mathrm{BrdU}^{+}$ follicles (with and without bTSH) were again significantly greater in Wistar rats than in BB-DP follicles of young rats (3-8 weeks of age): without bTSH stimulation there were $21 \pm 2 \%$ and $13 \pm 2 \%$ positive follicles respectively $(P<0 \cdot 05 ; n=6)$, and after bTSH stimulation there were $43 \pm 4 \%$ and $27 \pm 3 \%(P<0 \cdot 01 ; n=6)$. There was also no age-dependency with regard to this difference in BrdU uptake (pre- and hyperplastic periods). During the hyperplastic period (9-20 weeks of age), BrdU uptake in Wistar and BB-DP rats respectively was: non-bTSH stimulated, $26 \pm 3 \%$ and $16 \pm 2 \%(P<0 \cdot 05 ; n=8) ; \mathrm{bTSH}$ stimulated, $61 \pm 4 \%$ and $39 \pm 3 \% \quad(P<0 \cdot 005 ; n=8)$. After bTSH stimulation, Wistar follicles often demonstrated 10-20 $\mathrm{BrdU}^{+}$nuclei per follicle, whereas BB-DP follicles never exceeded 5-10 $\mathrm{BrdU}^{+}$nuclei per follicle.

To study further whether the discrepancy between our in vivo (goitre) and in vitro (low proliferation) data could be attributable to a different response of BB-DP and Wistar thyroid follicles towards other growth factors contaminating the bTSH preparation, we performed additional experiments with rhTSH with a purity greater than $99 \%$. We obtained data similar to those with bTSH, namely a lower $\left[{ }^{3} \mathrm{H}\right] \mathrm{TdR}$ uptake in BB-DP thyroid follicles than in Wistar follicles.

Production of thyroid hormones and thyroglobulin by in vitro cultured rat thyroid follicles

For both the Wistar and the BB-DP follicles, $100 \mathrm{mU} / \mathrm{ml}$ bTSH appeared to be the optimal concentration for the measurement both of hormone secretion and of cytokine production. Addition of 6-propyl-2-thiouracil (Sigma; $2 \mathrm{mM}$ ) during the culture period inhibited basal and bTSH-induced hormonal levels in the culture supernatants (data not shown), indicating that the hormones assayed in the supernatant were mainly produced by the cells during the culture period rather than released via non-specific mechanisms. 


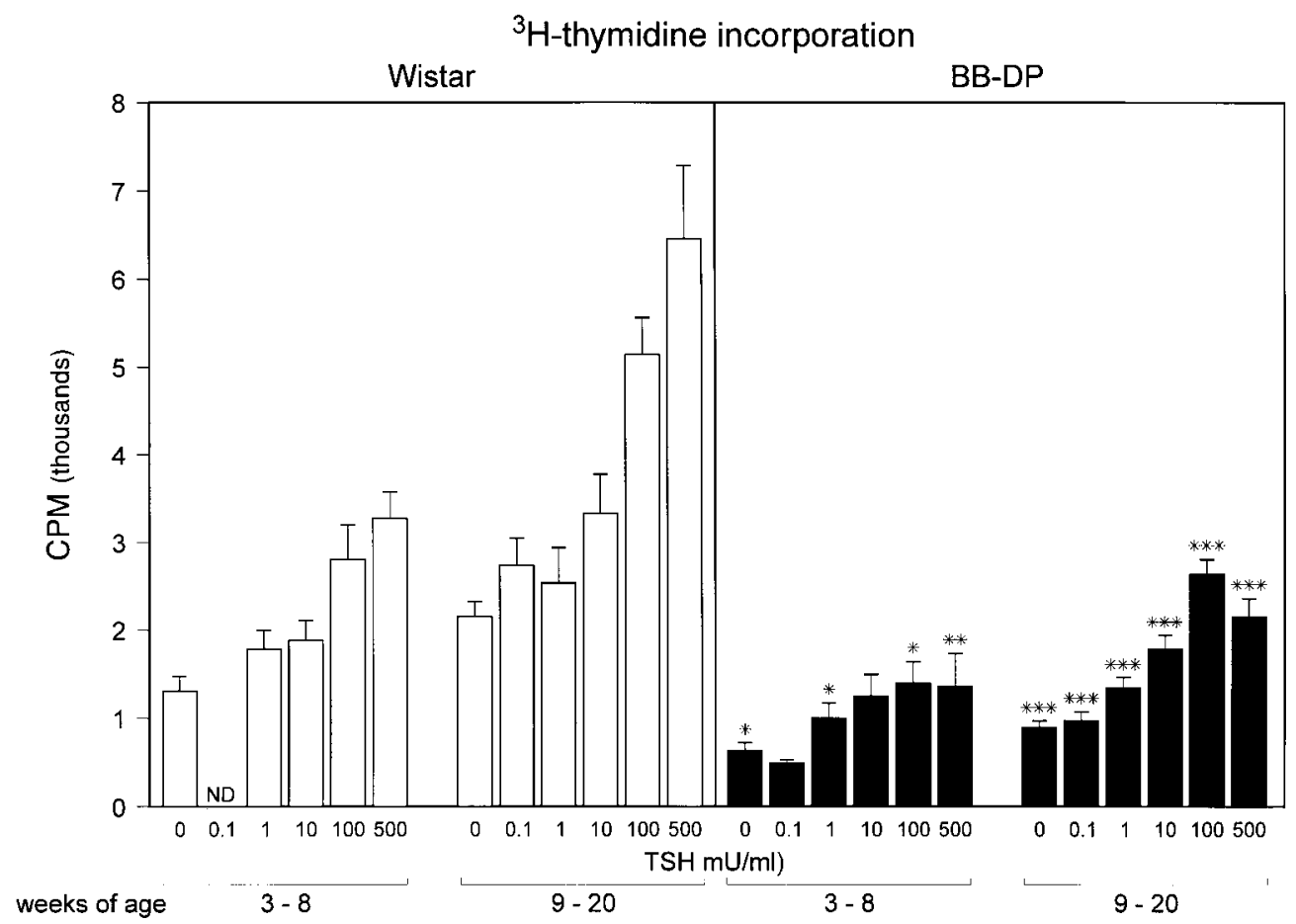

Figure 2 Uptake of $\left[{ }^{3} \mathrm{H}\right] \mathrm{TdR}$ by cultured BB-DP $(\boldsymbol{\square})$ and Wistar $(\square)$ rat thyroid follicles (1000/well) in the absence or presence of various dosages of bTSH. Follicles were isolated from two age groups: 3-8 weeks and 9-20 weeks of age. Means $(n \geq 6) \pm$ S.E.M. are shown. ${ }^{*} P<0 \cdot 05,{ }^{* *} P<0 \cdot 01,{ }^{* *} P<0 \cdot 001$ compared with Wistar (age-matched groups; Wilcoxon's rank sum test).

Table 1 In vitro production of $\mathrm{T}_{3}, \mathrm{~T}_{4}$, IL-6 and thyroglobulin (Tg) by BB-DP and Wistar rat thyroid follicles. Values are means \pm S.E.M.

\begin{tabular}{|c|c|c|c|c|c|c|c|c|}
\hline & \multicolumn{4}{|c|}{ 3-8 weeks of age } & \multicolumn{4}{|c|}{ 9-20 weeks of age } \\
\hline & BB-DP rat & $n$ & Wistar rat & $n$ & BB-DP rat & $n$ & Wistar rat & $n$ \\
\hline \multicolumn{9}{|l|}{ Unstimulated } \\
\hline $\mathrm{T}_{4}(\mathrm{fmol} / 2000$ follicles $)$ & $890 \pm 87^{*}$ & 10 & $1378 \pm 171$ & 10 & $1518 \pm 209^{*}$ & 9 & $854 \pm 113$ & 8 \\
\hline Ratio $\mathrm{T}_{3} / \mathrm{T}_{4}$ & $0 \cdot 22 \pm 0 \cdot 02^{\star * *}$ & 10 & $0 \cdot 08 \pm 0 \cdot 01$ & 10 & $0 \cdot 21 \pm 0.05^{*}$ & 9 & $0.33 \pm 0.06$ & 7 \\
\hline $\mathrm{Tg}$ (ng/2000 follicles) & $2638 \pm 229$ & 3 & $2884 \pm 390$ & 5 & $2935 \pm 640$ & 6 & $3128 \pm 352$ & 6 \\
\hline \multicolumn{9}{|l|}{ TSH $(100 \mathrm{mU} / \mathrm{ml})$-stimulated } \\
\hline $\mathrm{T}_{3}$ (fmol/2000 follicles) & $268 \pm 28^{*}$ & 10 & $163 \pm 26$ & 10 & $335 \pm 35$ & 27 & $312 \pm 31$ & 14 \\
\hline $\mathrm{T}_{4}(\mathrm{fmol} / 2000$ follicles $)$ & $1262 \pm 154$ & 10 & $1771 \pm 239$ & 10 & $2130 \pm 244^{* *}$ & 9 & $968 \pm 142$ & 8 \\
\hline Ratio $\mathrm{T}_{3} / \mathrm{T}_{4}$ & $0 \cdot 22 \pm 0 \cdot 02^{* *}$ & 10 & $0 \cdot 10 \pm 0 \cdot 02$ & 10 & $0 \cdot 26 \pm 0 \cdot 05$ & 9 & $0 \cdot 37 \pm 0.08$ & 7 \\
\hline $\operatorname{Tg}$ (ng/2000 follicles) & $2675 \pm 62^{*}$ & 3 & $3708 \pm 291$ & 5 & $3425 \pm 626$ & 6 & $3349 \pm 416$ & 6 \\
\hline IL-6 (units/2000 follicles) & $232 \pm 53$ & 7 & $154 \pm 53$ & 4 & $477 \pm 99 *$ & 3 & $190 \pm 35$ & 6 \\
\hline
\end{tabular}

$n$, Number of experiments. ${ }^{*} P<0 \cdot 05,{ }^{* *} P<0 \cdot 01,{ }^{* * *} P<0 \cdot 001$ compared with age group-matched Wistar rats (Wilcoxon's rank sum test).

BB-DP follicles isolated at young age (3-8 weeks of age; pre-hyperplastic stage) showed a significantly lower basal $\mathrm{T}_{4}$ secretion compared with age-matched Wistar follicles (Table 1). The $\mathrm{T}_{3}$ output, however, was significantly greater in the BB-DP follicles (both basal and bTSHstimulated, Table 1), resulting in a relatively high $\mathrm{T}_{3} / \mathrm{T}_{4}$ ratio in very young BB-DP rats compared with Wistar rats. The bTSH-stimulated production of thyroglobulin from BB-DP follicles was less than that in Wistar follicles (Table 1).

BB-DP follicles isolated from rats of 9 weeks of age and older (hyperplastic stage) demonstrated in vitro a clear increase in $\mathrm{T}_{4}$ production compared with BB-DP follicles isolated from younger rats (Table 1). This increased 
production after 9 weeks of age was also significantly enhanced (both basal and bTSH-stimulated) compared with that in Wistar follicles of the same age group. Production of $\mathrm{T}_{3}$ and thyroglobulin did not differ between follicles of BB-DP and Wistar rats.

Morphological signs of hypermetabolism of the thyrocytes at the time of in vitro enhanced $\mathrm{T}_{4}$ production were also evident in the BB-DP hyperplastic goitres. Pathologists often use the size of the nuclear area of thyrocytes as a parameter of the metabolic state of the cell, and we also measured this parameter in thyroid sections (Klencki et al. 1994, Paschke et al. 1995): the nuclear area of thyrocytes was significantly greater in BB-DP rats of 14 and 20 weeks of age than in Wistar rats (Fig. 1c).

\section{Production and expression of IL-6, MCP-1, TNF- $a$ and ICAM-1}

On cryostat sections, thyrocytes of BB-DP rats in the period before hyperplastic goitre development (before 9 weeks of age) and of Wistar rats were seen to be stained with anti-IL-6 antibodies. The immunohistochemical technique used did not allow a reliable quantification of this cytokine. No staining was observed with antibodies against MCP-1 and TNF- $\alpha$. ICAM-1 expression was modest and restricted to some large venules in sections of thyroid glands of both the BB-DP and Wistar rat.

In the period during hyperplastic goitre development (from 9 weeks of age onwards), thyrocytes of BB-DP and Wistar rats were again positively stained for IL- 6 . TNF- $\alpha$ and MCP-1 were detected at this time, but only when infiltrates of lymphoid cells were present in the thyroid glands of the BB-DP rats (aged 18 weeks and over). In these cases, cytokine expression was restricted to the areas of leucocytic infiltration, and in these areas a high expression of ICAM-1 was also observed on blood vessels and leucocytes. Thyrocytes were negative.

IL-6 was clearly detectable in the culture supernatants of rat thyroid follicles. Before 9 weeks of age, there was no difference with regard to IL-6 production between BB-DP and Wistar thyroid follicles (Table 1). However, BB-DP follicles isolated after 9 weeks of age produced significantly more IL-6 than Wistar follicles, when stimulated with bTSH (Table 1).

Release of MCP-1 was highly variably, ranging from 0 to $580 \mathrm{pg} / 2000$ follicles, and no difference was found between BB-DP rat and Wistar rat thyroid follicles. Furthermore, MCP-1 release was not upregulated by bTSH.

TNF- $\alpha$ was not produced by BB-DP or Wistar thyroid follicles at any age.

\section{Discussion}

Our data show that BB-DP rats develop a small goitre with histomorphological signs of hyperplasia and hyperfunction between the age of 9-12 weeks. Our in vitro findings of a lower proliferation rate of 'hyperplastic' BB-DP thyrocytes kept in follicle culture, compared with that in Wistar thyrocytes, are thus puzzling. There are a number of possible explanations for the discrepancy between the in vivo and in vitro data. First, the inclusion of FCS in our culture system may have exposed the thyrocytes to uncharacterized growth factors (or growth inhibitors); our experiments therefore cannot exclude differences in sensitivity for such factors between the two different strains of rats. Secondly, the $\left[{ }^{3} \mathrm{H}\right] \mathrm{TdR}$ uptake into in vitro cultured thyrocytes may not reflect true cell proliferation (Maurer 1981). However, our experiments using aphidicolin, X-irradiation and BrdU labelling indicate that our data represent valid measurement of such proliferation. If valid, these data underline once more the danger of extrapolating in vitro data to the in vivo situation. In vivo goitre development is, indeed, far more complex than in vitro thyrocyte proliferation. First, goitre development is influenced by growth factors produced by cells other than thyrocytes - that is, by stromal cells normally present in the vicinity of the thyrocytes, such as fibroblasts and endothelial cells (Bechtner et al. 1993). Such cells were virtually absent from our in vitro follicle culture system. It is known also that the addition of matrix factors to thyroid follicle cultures greatly alters the proliferative rate of the thyrocytes (Toda et al. 1995). Secondly, goitre development is not only the outcome of thyrocyte proliferation, but also influenced by the rate of apoptosis of thyrocytes. Therefore, further experiments, such as in vivo BrdU labelling and the use of apoptosis markers, are needed, to shed more light on the discrepancy we have described here.

Regardless of the need to explore that discrepancy further, there is one striking similarity of our in vitro observations with those made in the OS chicken: a decreased in vitro growth rate of thyrocytes in the pre-autoimmune stage (Truden et al. 1983). It has been suggested that this abnormal, intrinsic, low proliferative rate of OS chicken thyrocytes reflected an inborn derangement of function (Truden et al. 1983) - that is, a defect in the handling of iodine (fewer I atoms were found to be built into the chicken thyroglobulin; Sundick 1989). Other pre-autoimmune thyroid abnormalities found in the OS chicken included TSH-independent hyperfunction, such as a high oxidative metabolism, a high iodine uptake and an incomplete suppression of this uptake (Sundick 1989). These signs of hypermetabolism were suggested to be mechanisms compensating for the iodine-handling defect.

It is tempting to speculate that the hyperplastic goitre development and the relatively high follicular $\mathrm{T}_{4}$ output of our BB-DP rats of 9 weeks and older also represent compensatory mechanisms for the postulated mild defect in the handling of iodine. Evidence for such a mild defect (a low iodine/thyroglobulin ratio, and an abnormal, incomplete Wolff-Chaikoff effect) has been reported by Li \& Boyages (1994). We have observed that young BB-DP 
rats are extremely sensitive to perchlorate discharge and respond to low iodine diets with an extremely low plasma concentration of $\mathrm{T}_{4}$ (Mooij et al. 1992, Mooij 1993). However, the existence of a mild defect in iodine organification in BB-DP rats has also been disputed (Rajatanivan et al. 1983), and clearly more investigations are needed in the very young BB-DP rat (less than 9 weeks old) to establish or refute such metabolic abnormality and its compensations. In patients with Hashimoto's thyroiditis, however, organification defects have been well described (Takeuchi et al. 1970).

Whatever the reasons may be for the small goitre development in the BB-DP rat, we believe that the dendritic cells accumulate in such hyperplastic thyroids to serve a function: the regulation of the abnormal growth rate and metabolism of the thyrocytes (see Introduction).

What factors and cytokines are attracting these dendritic cells to the BB-DP rat thyroid? Histologically, we could not find a difference in ICAM-1 expression between BB-DP and Wistar thyroid endothelial cells in the prethyroiditis phase. However, after the development of focal thyroiditis in the BB-DP rat, ICAM-1 became clearly expressed on the endothelial cells in the thyroiditis areas, suggesting a role of this adhesion molecule late in the autoimmune process.

MCP-1 was produced in vitro by thyroid follicles, but in variable quantities, and there was no difference between BB-DP and Wistar thyroid follicles. Low levels of MCP1 have also been observed in primary cultures of human thyrocytes isolated from patients with Graves' disease. Only after stimulation with cytokines such as IL-1- $\alpha$, TNF- $\alpha$ and, to a lesser extent, IFN- $\gamma$, were significant amounts of MCP-1 detected (Kasai et al. 1996).

BB-DP thyroid follicles isolated in the hyperplastic goitre phase did, however, produce more IL-6 than Wistar thyrocytes. Contaminating leucocytes could not have been the source of this IL-6, as such contaminating cells were not present in our culture system. In vitro IL-6 production by thyrocytes has been reported before. It is stimulated by TSH (see also this report), IL-1- $\alpha$ and epidermal growth factor (Hirano et al. 1990, Bartalena et al. 1995). IL-6 has a wide variety of activities: it is involved in the regulation of the immune response by an enhancement of $\mathrm{T}$ cell proliferation, a stimulation of $\mathrm{B}$ cells to produce antibodies and an enhancement of the activity of GM-CSF (Hirano et al. 1990). It also has a role in the transition of monocytes to dendritic cells (Mooij et al. 1994, Peters et al. 1996), hence a role of this cytokine in the intrathyroid accumulation of dendritic cells in BB-DP rats is likely. IL-6 also has a role in the stimulation of growth of thyrocytes (Nishiyama et al. 1993, Shimomura et al. 1994), and it is thus intriguing that the BB-DP thyrocytes, although having a low in vitro proliferative rate, produced more IL-6 (see above).

With regard to TNF- $\alpha$, we were unable to detect, either in situ or in vitro (culture of isolated follicles), a noteworthy production of TNF- $\alpha$ by thyrocytes at a stage at which lymphocytes had not yet infiltrated the thyroid.

With regard to yet other factors that play a part in accumulation of dendritic cells, namely autoantigens, we found no noteworthy difference between the production of thyroglobulin in BB-DP and Wistar rat thyroid follicles kept in culture. This might indicate that the expression of this autoantigen does not play a major part in the increased accumulation of the APCs. However, we cannot exclude the possibility that the degree of iodination of thyroglobulin is important (Sundick 1989), and that other autoantigens, such as thyroperoxidase, are expressed at a higher level in our BB-DP thyrocyte cultures.

In conclusion, our report describes hyperplastic goitre development in the BB-DP rat at a stage when the thyroid autoimmune reaction is initiated. At the same time there was also an increased production of $\mathrm{T}_{4}$ and IL- 6 by the thyrocytes. It is conceivable that these thyroid abnormalities create a micromilieu that favours the attraction of APCs and the initiation of the thyroid autoimmune response.

\section{Acknowledgements}

This work was supported by NWO-MEDIGON (grant numbers 900-540-154 and 903-40-167). Dr JJ M de Vijlder advised us on the thyroglobulin assay. We are indebted to $\mathrm{Mr}$ Tar van Os for preparation of the figures, Mr Ed Landsbergen and Mr John Mahabier for animal care, and Mrs Petra Assems for typographical support. The Department of Pathology, EUR, prepared the sections for haematoxylin-eosin staining.

\section{References}

Aarden LA, Groot de ER, Schaap OL \& Lansdorp PM 1987 Production of hybridoma growth factor by human monocytes. European Journal of Immunology 17 1411-1416.

Allaerts W, Tijssen AMI, Jeucken PHM, Drexhage HA \& Koning de J 1994 Influence of folliculo-stellate cells on biphasic luteinizing hormone secretion response to gonadotropin-releasing hormone in rat pituitary cell aggregates. European Journal of Endocrinology 130 530-539.

Allaerts W, Fluitsma DM, Hoefsmit ECM, Jeucken PHM, Morreau H, Bosman FT \& Drexhage HA 1996 Immunohistochemical, morphological and ultrastructural resemblance between dendritic cells and folliculo-stellate cells in normal human and rat anterior pituitaries. Journal of Neuroendocrinology 8 17-29.

Allaerts W, Jeucken PHM, Debets R, Hoefakker S, Claassen E \& Drexhage HA 1997 Heterogeneity of pituitary folliculo-stellate cells: implications for interleukin-6 production and accessory function in vitro. Journal of Neuroendocrinology 9 43-53.

Ambesi-Impiombato FS, Parks LAM \& Coon H 1980 Culture of hormone dependent functional epithelial cells from rat thyroids. Proceedings of the National Academy of Sciences of the USA 77 3455-3459.

Bartalena L, Brogioni S, Grasso L \& Martino E 1995 Interleukin-6 and the thyroid. European Journal of Endocrinology 132 386-393.

Bechtner G, Rieder B, Linsemaier U, Kellermann J, Greil W \& Gärtner R 1993 Isolation and partial molecular characterization of 
basic fibroblast growth factor from isolated porcine thyroid follicles and entire porcine thyroid glands. Acta Endocrinologica 129 458-466.

Brännström M \& Norman RJ 1993 Involvement of leucocytes and cytokines in the ovulatory process and corpus luteum function. Human Reproduction 8 1762-1775.

Denef J-F, Björkman U \& Ekholm R 1980 Structural and functional characteristics of isolated follicles. Journal of Ultrastructure Research $\mathbf{7 1}$ 185-202.

Diamond JR \& Pesek I 1991 Glomerular tumor necrosis factor and interleukin during acute aminonucleoside nephrosis. An histochemical study. Laboratory Investigation 64 21-28.

Eertwegh van den AJM, Fasbender MJ, Schellekens MM, Oudenaren van A, Boersma WJA \& Claassen E 1991. In vivo kinetics and characterization of IFN- $\gamma$-producing cells during a thymusindependent immune response. Journal of Immunology 147 439-446.

Espevik T \& Nissen-Meyer J 1986 A highly sensitive cell line, WEHI 164 clone 13, for measuring cytotoxic factor/tumor necrosis factor from human monocytes. Journal of Immunological Methods 95 99-105.

Gaytan F, Bellido C, Aguilar E \& Rooijen van N 1995 Pituitarytesticular axis in rats lacking testicular macrophages. European Journal of Endocrinology 132 218-222.

Hala K, Malin G, Dietrich H, Loesch U, Boeck G, Wolf H, Kaspers B, Geryk J, Falk M \& Boyd RL 1996 Analysis of the initiation period of spontaneous autoimmune thyroiditis (SAT) in Obese Strain (OS) of chickens. Journal of Autoimmunity 9 129-138.

Hirano T, Akira S, Taga T \& Kishimoto T 1990 Biological and clinical aspects of interleukin 6. Immunology Today 11 443-449.

Hoek A, Allaerts W, Leenen PJM, Schoemaker J \& Drexhage HA 1996 Dendritic cells and macrophages in the pituitary and the gonads. Evidence for their role in the fine regulation of the reproductive endocrine response. European Journal of Endocrinology 136 8-24.

Kabel PJ, Voorbij HAM, Haan de M, Gaag van der RD \& Drexhage HA 1988 Intrathyroidal dendritic cells. Journal of Clinical Endocrinology and Metabolism 65 199-207.

Kasai K, Banba N, Motohashi S, Hattori Y, Manaka K \& Shimoda S-I 1996 Expression of monocyte chemoattractant protein-1 mRNA and protein in cultured human thyrocytes. FEBS Letters 394 137-140.

Katabuchi H, Fukumatsu Y, Araki M, Suenaga Y, Ohtake H \& Okamura H 1996 Role of macrophages in ovarian follicular development. Hormone Research 46 45-51.

Klencki M, Slowinska-Klencka D, Kunert-Radek J \& Lewinski A 1994 Melatonin-induced decrease of the size of thyrocyte nuclei in rat thyroids incubated in vitro. Cytobiology 78 159-162.

Li M \& Boyages SC 1994 Iodide induced lymphocytic thyroiditis in the $\mathrm{BB} / \mathrm{W}$ rat: evidence of direct toxic effects of iodide on thyroid subcellular structure. Autoimmunity 18 31-40.

Many M-C, Maniratunga S, Varis I, Dardenne M, Drexhage HA \& Denef J-F 1995 Two step development of a Hashimoto-like thyroiditis in genetically autoimmune prone non obese diabetic (NOD) mice. Effects of iodine-induced cell necrosis. Journal of Endocrinology 147 311-320.

Maurer HR 1981 Potential pitfalls of $\left[{ }^{3} \mathrm{H}\right]$ thymidine techniques to measure cell proliferation. Cell and Tissue Kinetics 14 111-120.

Mooij P 1993 The thyroid, iodine and autoimmunity. Academic Thesis, Erasmus University Rotterdam.

Mooij P, Wit de HJ \& Drexhage HA 1992 Thyroid autoimmune prone rats are able to compensate for moderately low iodine regimens, quickly restoring full euthyroidism. Journal of Endocrinological Investigation 15 (suppl 2-5) 105 (Abstract).

Mooij P, Wit de HJ, Bloot AM, Wilders-Truschnig MM \& Drexhage HA 1993 a Iodine deficiency induces thyroid autoimmune reactivity in Wistar rats. Endocrinology 133 1197-1204.

Mooij P, Wit de HJ \& Drexhage HA 1993 b An excess of dietary iodine accelerates the development of a thyroid-associated lymphoid tissue in autoimmune prone BB rats. Clinical Immunology and Immunopathology 69 189-198.
Mooij P, Simons PJ, Haan-Meulman de M, Wit de HJ \& Drexhage HA 1994 The effect of thyroid hormones and other iodinated compounds on the transition of monocytes into veiled/dendritic cells: role of granulocyte-macrophage colony-stimulating factor, tumour necrosis factor-alpha and interleukin-6. Journal of Endocrinology 140 503-512.

Nishiyama S, Takada K, Tada H, Takano T \& Amino N 1993 Effect of interleukin-6 on cell proliferation of FRTL-5 cells. Biochemical and Biophysical Research Communications 192 319-323.

Okugawa T, Itoh M, Murata Y \& Seo H 1995 Effect of aphidicolin on DNA synthesis in cultured human thyroid cells. Experimental and Clinical Endocrinology 103 88-93.

Paine R, Rolfe MW, Standiford TJ, Burdick MD, Rollins BJ \& Strieter RM 1993 MCP-1 expression by rat type II alveolar epithelial cells in primary culture. Journal of Immunology $\mathbf{1 5 0}$ 4561-4570.

Paschke R, Eck T, Herfurth J \& Usadel KH 1995 Stimulation of proliferation and inhibition of function of xenotransplanted human thyroid tissue by epidermal growth factor. Journal of Endocrinological Investigation 18 359-363.

Peters JH, Gieseler R, Thiele B \& Steinbach F 1996 Dendritic cells: from ontogenetic orphans to myelomonocytic descendants. Immunology Today 17 273-278.

Rajatanivan R, Fang SL, Like A \& Braverman LE 1983 Lymphocytic thyroiditis in the $\mathrm{BB} / \mathrm{W}$ diabetic rat; no evidence of thyroid dysfunction. Clinical Research 31275 (Abstract).

Sakanashi Y, Takeya M, Yoshimura T, Feng L, Morioka T \& Takahashi K 1994 Kinetics of macrophage subpopulations and expression of monocyte chemoattractant protein-1 (MCP-1) in bleomycin-induced lung injury of rats studied by a novel monoclonal antibody against rat MCP-1. Journal of Leukocyte Biology 56 741-750.

Shimomura N, Itoh M, Okugawa T, Murata Y \& Seo H 1994 Effects of interleukins on EGF-stimulated growth promotion in human thyroid cells: differential modifications by IL-2 and IL-6 in Graves' and normal thyroid cells. Endocrine Regulations 28 55-65.

Spinel-Comez C, Colin I, Hove van den M-F \& Denef J-F 1990 Correlated morphological and functional study of isolated rat thyroid follicles in suspension culture. Molecular and Cellular Endocrinology $\mathbf{7 1}$ 141-153.

Sundick RS 1989 Target organ defects in thyroid autoimmune disease. Immunologic Research 8 39-60.

Takeuchi K, Suzuki H, Horiuchi Y \& Mashimo K 1970 Significance of iodine-perchlorate discharge test for detection of iodine organification defect of the thyroid. Journal of Clinical Endocrinology 31 144-146.

Toda S, Matsumura S, Yonemitus N, Fujitiani N, Terayama K, Funatsumaru S \& Sugihara H 1995 Effects of various types of extracellular matrices on adhesion, proliferation, differentiation, and c-fos protein expression of porcine thyroid follicle cells. Cell Structure and Function 20 345-354.

Truden JL, Sundick RS, Levine S \& Rose NR 1983 The decreased growth rate of obese strain chicken thyroid cells provides in vitro evidence for a primary target organ abnormality in chickens susceptible to autoimmune thyroiditis. Clinical Immunology and Immunopathology 29 294-305.

Voorbij HAM, Kabel PJ, Jeucken PHM, van der Gaag RD, de Baets MH \& Drexhage HA 1990 Dendritic cells and class II MHC expression on thyrocytes during autoimmune thyroid disease of the $\mathrm{BB}$ rat. Clinical Immunology and Immunopathology 55 9-22.

Wilders-Truschnig MM, Kabel PJ, Drexhage HA, Beham A, Leb G, Eber O, Hebenstreit J, Loidolt D, Dohr G \& Lanzer G 1989 Intrathyroidal dendritic cells, epitheloid cells, and giant cells in iodine deficient goiter. American Journal of Pathology 135 219-225.

Received 30 April 1997

Revised manuscript received 19 September 1997 Accepted 28 October 1997 